\title{
COPING STRATEGIES WITH MUTUAL COOPERATION AND USE OF LOCAL RESOURCES ON DISASTER BY NEPALESE RURAL PEOPLE: A CASE FROM NUWAKOT DISTRICT, NEPAL
}

\author{
Dipendra Dhakal*, Keiko Yoshino \\ Department of Food Environment Economics, Tokyo University of Agriculture, Tokyo, Japan. \\ * Corresponding author: E-mail: dipendha@gmail.com
}

Citation: Dhakal, D., Yoshino, K. 2020. Coping Strategies with Mutual Cooperation and Use of Local Resources on Disaster by Nepalese Rural People: A Case from Nuwakot District, Nepal, J. Asian Rur. Stud. 4(2): 178-187

\begin{abstract}
Nepal is vulnerable to environmental disasters such as earthquakes, landslides, floods and hurricanes. These disasters disproportionately affect rural life. Disaster risks are often approached in a purely technical and physical manner, but people's behaviour in the face of natural hazards and disasters is influenced by various factors such as historical, economic, political and socio-cultural factors. This case uses a post-disaster resilience assessment focusing on cooperation during the recovery after a severe earthquake that hit central Nepal in 2015 which impacted rural communities. This paper analyses the people's behaviour and its basic logic at post-earthquake recovery from a socio-cultural aspect focusing on the gaun, the basic minimal informal social unit. Special consideration was made to the ethnic heterogeneity of the communities studied. For the purpose of this study, key informants interview (KII), group discussion and transect walk were used. This study finds that gaun based local resources are traditional and primary resources for people's daily life but the ward and VDC based resources are newly formed. Various forms of cooperation were observed regardless ethnicity at the gaun level. This study further reveals that local people's activities towards the post-disaster recovery can be described in three periods. They are: emergent, resilient, reconstruction periods. On the basis of the study of these periods for post-disaster recovery, a very good social relationship among gaun people at emergency was realized.
\end{abstract}

Keywords: Coping Strategies; Rural Cooperation; Local Resources; Nepal Earthquake; Ethnicity

\section{Introduction}

Nepal is a small landlocked country with an estimated per capita Gross Domestic Product (GDP) of USD 682 (World Bank, 2016) and a population of 26.4 million people (CBS, 2011), 85\% of which are based in rural areas. Nepal is vulnerable to natural hazards and faces a wide variety and significant number of natural hazards every year (DPNet Nepal, 2009). The country's hazards include epidemics, floods, landslides and mudslides, urban and wild fires, glacier lake outburst floods, wind storms, cold and hot waves, road accidents, drowning incidents, landmines and earthquake (MoHA and DPNet Nepal, 2009). Various rolling vulnerability assessments conducted in Nepal indicate an increase in the frequency of occurrence of natural hazards. Among these disasters, earthquakes are one of the major disaster in Nepal. 
On the $25^{\text {th }}$ April 2015, a massive 7.8 magnitude earthquake struck in Nepal, just northwest from Kathmandu. The loss of life and damage to property was at a massive scale, affecting 31 districts out of 75 districts of the country. It was the worst quake to strike the region in more than 80 years. The major shock was followed by more than 600 aftershocks with magnitudes of up to 7.3. The area was hit with a big aftershock 7.3 magnitude just 17 days later, on May 12, causing further damage and suffering for those who had survived the initial disaster. Approximately, 8 million were affected, around 9,000 were killed, at least 22,200 were injured, more than 505,000 houses were destroyed and about 279,000 houses were damaged. Overall $40 \%$ area of Nepal was affected by that massive earthquake (Mercy corps 2015). The Nepal Planning Commission estimated that the total value of loss and damage due to the earthquake to be USD 7 billion, which is equivalent to about one-third of the country's gross domestic product (PDNA, Vol. A, 2015). The earthquake on April 25 th 2015 mostly affected the hilly region of the country which is home to those that are economically poor and excluding Kathmandu, is constrained in their development opportunities due to the remoteness of their location. Poverty rates also show marked differences by ecological zone with $32.6 \%, 34.5 \%$ and $27.6 \%$ in Mountains, Hills and Terai respectively (CBS, 2006).

Hewitt (2008) pointed out that socio-cultural factors influence the vulnerability of certain groups to disasters in communities. He states that disaster risks are often approached in a purely technical and physical manner, but people's behaviour in the face of natural hazards and disasters is influenced by various socio-economic factors such as historical, economic, political and socio-cultural factors. Socio-cultural attitudes are particularly important as they can influence readiness for disaster management. This view is supported by Kapucu (2008) in the case of Florida hurricane, who suggests that community responsive preparatory systems are the best way and that history has proven that bottom-up approaches to disaster risk mitigation work is best. She further suggests that real disaster preparedness for citizen means being ready to cooperate with social factors like family, friends, neighbours and social organizations when a disaster or an emergency strikes.

The government of Nepal has attempted to manage the disasters not only through formal government instruments but through informal civic involvement. It is largely because of the shortage of budget and remoteness of the rural area but the importance of collective action is understood (MoHA and DPNet, 2009).

For the countries where the multiple ethnic groups reside, ethnicity may influence on the damage and recovery from disaster. Bolin (1976) reported that domestic recovery processes depend on social characteristics, such as household size, income, culture, ethnicity, etc. But Wang et al. (2017) found no differences in the recovery process among three ethnic groups from a case study of the 2008 Magnitude 7.9 earthquake in China. They analysed that the shared same natural environment, equal governmental support, and similarity of educational level were the factors. Our study also shows the ethnic relations among different ethnic groups on the domestic recovery.

With regard to the Nepal earthquake 2015, Mishra et al. (2017) conducted research to identify the influencing factors at community level for their post- recovery. They listed six factors- natural resources endowment, physical connectivity, access to external development services, entrepreneurship, social homogeneity and social economy, which are generally regarded to be important factors for quick recovery and examine. They 
found that good accessibility may adversely function as reliability and showed the example that remote community performed strong unity and self-reliance.

They also showed doubt as to the importance of homogeneity of the community. Findings of Mishra et al. are very important, but their results are not clear as they themselves pointed out. It may be partly due to that they treated wards as communities. Wards are the minimum formal unit of local administration, but for the local people, autonomous local units are gaun which is much smaller than wards. Basically, local people's behaviour and cultural norms are based on gaun. Therefore, this paper analysed the local people's behaviour and its basic logic at post-earthquake recovery from socio-cultural aspect focusing on gauns.

\section{Study Area and Methodology}

The Betini Village Development Committee (VDC) in Nuwakot district, located 90 $\mathrm{km}$ from Kathmandu, was selected as the primary research area. Nuwakot district was one of the most heavily affected district (severely hit) categorized by the government, with approximately, 1,000 people were killed, 1,311 people were injured, 30,000 houses were fully damaged, 15,000 houses were partially damaged. In total, $51 \%$ of population of Nuwakot were affected (DDRC, Nuwakot, 2015) by the massive earthquake. The population of Nuwakot district is 277,471 and includes multiple ethnic groups: Tamang (40.2\%), Bahun (19\%), Chhetri (12.6\%), Newar (7\%), Dalit (7\%), Rai (4\%), Magar $(2 \%)$ and others $(6 \%)$ (CBS: National population and housing census, 2011). Out of 61 Village Development Committees (VDC) and one municipality of Nuwakot district, Betini VDC was one of the most affected area.

There are two formal administrative units in the local level of the country. They areVillage Development Committee (VDC) and wards. Each VDC is further divided into several wards. The VDC is the administrative body of the local government, and is responsible for providing services and conducting development activities. The ward is the smallest unit of political division and a minimal unit of local government. There is a ward committee which officially connects the VDC with inhabitants.

In Betini VDC, there are 9 wards, of which the three eastern wards $(7,8,9)$ where the damage was most severe, were selected as the sample research area. Figure 1 indicates the Nuwakot district of Nepal and the research site which lies in the Betini VDC. Key informants interview (KII), group discussions and transect walk were conducted in order to know the use and management system of primary local resources which are indispensable for daily life. The use of local resources such as drinking water, community forest, communal land/community building, religious resources and their managing social organizations including voluntary organizations were also interviewed (Table 1). 

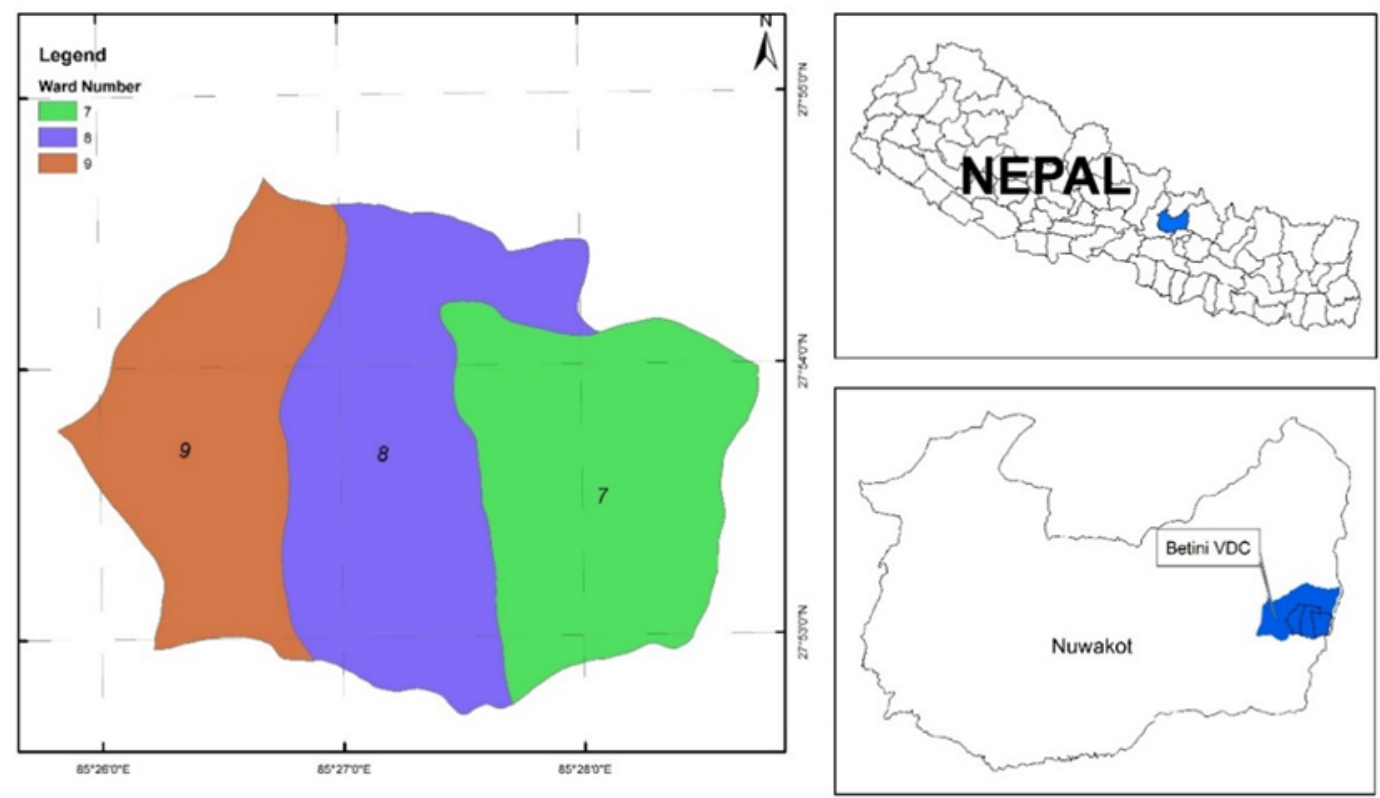

Figure 1 Research Site (Betini, Nuwakot)

Source: Author

Table 1. List of key informants and type of information collected

\begin{tabular}{|c|c|c|}
\hline No & Key Informants & Information \\
\hline 1. & School Teachers/ Local Gov. officials & General information on wards and gauns. \\
\hline 2. & Ethnic Group Leaders/Gaun leaders & $\begin{array}{l}\text { Information on religious and cultural events, } \\
\text { community building, use of primary local } \\
\text { resources and their management system. }\end{array}$ \\
\hline 3. & Aged people & Disaster history, communal land (ailani) \\
\hline 4. & Youth, aged people & Various information from different age group \\
\hline 5. & Women Social Group & Gender interference and difficulties \\
\hline 6. & $\begin{array}{l}\text { Youth-club member, Community forest } \\
\text { management committee, Community } \\
\text { drinking water management committee }\end{array}$ & $\begin{array}{l}\text { Role of existing social organizations during the } \\
\text { disaster for recovery }\end{array}$ \\
\hline
\end{tabular}

Source: Designed by authors

\section{Result and Discussions}

\subsection{Ethnic Composition}

Table 2 shows that the Tamang (81.3\%) are the majority group in the community, followed by the Gurung people $(8.7 \%)$ and Sherpa people $(7.3 \%)$ as the second and third large position group with the Dalit people (2.6\%) having the lowest population in the research area. The Tamang people has the largest population $(81 \%$ and $40.2 \%)$ in the research area and Nuwakot district respectively but Tamang people has less population (5.8\%) at national level. Likewise, Gurung (1.97\%) and Dalit (4.5\%) also constitute less populated group and Sherpa $(0.43 \%)$ is the lowest populated group in Nuwakot district and national level too. Chhetri and Bahun are not found in the research area but table-2 shows that Chhetri and Bahun are majority groups which constitute 
$12.6 \%$ and $19 \%$ population in Nuwakot and; $17 \%$ and $12 \%$ respectively at national level of the total population. Thus, the research area has the domination of Tamang people but the study focuses to the marginal ethnic group people (Dalit) considering as multiethnic community.

Table 2. Distribution of population by ethnic groups in research area

\begin{tabular}{|c|c|c|c|c|c|c|c|c|c|c|c|c|c|}
\hline \multirow[t]{2}{*}{ Ward No. } & \multicolumn{2}{|c|}{ Tamang } & \multicolumn{2}{|c|}{ Gurung } & \multicolumn{2}{|c|}{ Sherpa } & \multicolumn{2}{|c|}{ Dalit } & \multicolumn{2}{|c|}{ Chhetri } & \multicolumn{2}{|c|}{ Bahun } & \multirow[t]{2}{*}{ Total } \\
\hline & Popn. & $\%$ & Popn. & $\%$ & Popn. & $\%$ & Popn. & $\%$ & Popn. & $\%$ & Popn. & $\%$ & \\
\hline 7 & 750 & 67.7 & 250 & 22.6 & 108 & 9.7 & 0 & 0 & 0 & 0 & 0 & 0 & 1,108 \\
\hline 8 & 491 & 86.7 & 0 & 0 & 0 & 0 & 75 & 13.2 & 0 & 0 & 0 & 0 & 566 \\
\hline 9 & 1,096 & 91.3 & 0 & 0 & 104 & 8.6 & 0 & 0 & 0 & 0 & 0 & 0 & 1,200 \\
\hline Total & 2,337 & 81.3 & 250 & 8.7 & 212 & 7.4 & 75 & 2.6 & 0 & 0 & 0 & 0 & 2,874 \\
\hline Betini* & 4,020 & 86.8 & 250 & 5.4 & 212 & 4.6 & 75 & 1.6 & 74 & 1.6 & 0 & 0 & \\
\hline Nuwakot* & 111,579 & 40.2 & 3,843 & 1.4 & 906 & 0.3 & 19,492 & 7 & 34,938 & 12.6 & 52,658 & 19 & \\
\hline National* & $1,539,830$ & 5.8 & 522,641 & 1.97 & 112,946 & 0.43 & $1,258,554$ & 4.5 & $4,398,053$ & 17 & $3,226,903$ & 12 & \\
\hline
\end{tabular}

*The national population of the respective ethnic group as per the Central Bureaue of Statistics (CBS 2011)

Popn. = Population

Source: Field study, 2018

\subsection{Comparison of local resources in the research site}

A gaun is a minimal informal social unit for local inhabitants which independently governs local social, cultural and religious activities. Several gauns are found under one ward, and one gaun is comprised of single or plural ethnic groups. There are three local social units in rural Nepal: the VDC, the ward and the gaun. Contrary to VDCs and wards which are formal local units, the gaun is an informal local unit which is very close to inhabitants.

In wards 7,8 and 9, we found 15 gauns. The largest gaun has 80 households and the smallest gaun has 11 households. Among the 15 gauns, 11 guans were comprised of Tamang only and one was comprised of Sherpa only. The rest of the three gauns were comprised of multiple ethnic groups: Gurung, Tamang, Sherpa; Dalit, Tamang; Sherpa, Tamang respectively.

Table 3 shows the use of local resources and cooperation among social organizations at the three levels of local units that existed before the earthquake. With regards to the resources, many primary resources such as drinking water, irrigation water, Chautari/paty, ailani, community building, temples, crematorium, cemetery were found to be gaun based, while community forests are gaun or ward based depending on the area. Chautari/paty is the place where gaun people gather to discuss the common issues of gaun. Ailani is the land owned by the government but managed by gauns. Ailani is used for grazing, local communal events such as festivals based on ethnic groups, periodic markets, and sports events managed by youth clubs. Primary local resources are directly connected with the basic life of gaun people.

With regards to the organizations, there is a management body for primary local resources; these include, drinking water management committees, ethnic group societies called samaj of each ethnic group (Tamang samaj, Gurung samaj, Sherpa samaj, Dalit samaj), mutual help on agricultural activities (reciprocal), women saving credit groups, which were found to be gaun based. Community forest management committees and youth clubs were gaun based or ward based. In addition, women agricultural cooperatives and tourism infrastructure development committees were found to be ward 
based, while community study centres and community welfare societies (semigovernmental) were VDC based. Ward based and VDC based organizations were all newly established after 1999 and semi-governmental. The Women's saving credit group, responsible for micro-finance promoted by a local NGO, was only newly established organization at the gaun level.

Table 3. Resources in the research area

\begin{tabular}{|c|c|c|c|}
\hline & $\begin{array}{l}\text { Gaun (minimal informal social unit } \\
\text { for local inhabitants) }\end{array}$ & $\begin{array}{l}\text { Ward (minimal } \\
\text { formal administrative } \\
\text { unit of government) }\end{array}$ & $\begin{array}{l}\text { VDC- Village Development } \\
\text { Committee (governmental } \\
\text { administrative unit) }\end{array}$ \\
\hline Resources & $\begin{array}{l}\text { Drinking water } \\
\text { Irrigation water (streams) } \\
\text { Ailani* } \\
\text { Chautari/pati (the place where gaun } \\
\text { people gathered to discuss } \\
\text { the common issues of gaun) } \\
\text { Community building } \\
\text { Temples (religion based) } \\
\text { Crematorium and cemetery } \\
\text { (ethnicity based) }\end{array}$ & orest & \\
\hline Organizations & $\begin{array}{l}\text { Community Forest Ma } \\
\text { Community drinking water Youth } \\
\text { management committee } \\
\text { Irrigation water management } \\
\text { committee } \\
\text { Mutual help on agricultural works } \\
\text { and cultural works > perma } \\
\text { (reciprocal/individual) } \\
\text { Tamang Samaj, Gurung Samaj, } \\
\text { Sherpa Samaj, Dalit Samaj } \\
\text { (Samaj- association of people } \\
\text { with similar interest) } \\
\text { Women saving credit group (new) }\end{array}$ & $\begin{array}{l}\text { gement Comittee } \\
\text { lub } \\
\text { Primary schools } \\
\text { Tourism } \\
\text { infrastructure } \\
\text { development } \\
\text { committee } \\
\text { Women agricultural } \\
\text { cooperative }\end{array}$ & $\begin{array}{l}\text { High school } \\
\text { Community study center } \\
\text { Community welfare society } \\
\text { (semi governmental) }\end{array}$ \\
\hline Administrations & $\begin{array}{l}\text { General gathering of gaun people } \\
\text { (informal) }\end{array}$ & Ward office & $\begin{array}{l}\text { VDC office, Sub-health } \\
\text { Post, Agriculture Extension } \\
\text { Office, Veterinary Office. }\end{array}$ \\
\hline
\end{tabular}

*The land owned by government but managed by gaun people.

Source: Field study, 2018

It is obvious that the gauns are the basic traditional informal unit, and within gauns cooperation is observed regardless of ethnicity among multiple ethnic groups. Local resource such as drinking water is managed and distributed equally by gaun member as household level. Every representative of household regardless of ethnicity attends general gatherings to discuss the common issues of gaun. Religious resources are collectively managed by same religious ethnic groups. Just mutual help is generally observed within ethnicity and sometimes regardless of ethnicity in group or individual.

\subsection{Mutual Cooperation after the disaster}

The twin earthquake of 2015 ( $25^{\text {th }}$ April and $12^{\text {th }}$ May) in Nepal, brought the serious damage to inhabitants and they tried to manage and recover. There was struggle for recovery making full use of existing resources Their reactions changed by the elapse of 
time and it can be divided into three periods. They are- Emergent period (until after one week of aftershock and after one week, they got supports from local government and NGO's), Recovery period (they constructed temporary shelters) and Reconstruction period (they reconstructed permanent buildings).

In this section, local people's behavior towards disaster recovery is described on each period focusing on the resource utilization (local and outside resources, social networks, etc.).

\subsubsection{Emergent period}

After earthquake immediately, the gaun, people helped each other to the injured one to take to the hospital and the dead body for the funeral regardless of ethnicity. Most people shifted into the safe fallow land called ailani nearby gaun. Youth clubs provided the physical assistance to construct temporary shelter. During this period, people shared preserved foodstuff with others in their gaun regardless of ethnicity. However, tents and clothes were shared among relatives and family. After a few days, local NGOs and local governmental organizations supported by providing dry foods, good tents, drinking water pipes, first aid kits and general medicines. The sharing of foodstuffs among the ethnicities is not observed in normal period because they have their own sharing culture and tradition in normal period as well. However, in this emergent period, there was deep collaboration and mutual help among different ethnic groups of the gaun.

\subsubsection{Recovery period}

After the aftershock on May $12^{\text {th }}$, debris from damaged house was removed and new temporary houses were constructed through the mutual cooperation among people in gauns regardless of ethnicity as labour exchange called perma is typically done during normal period. As mentioned in Table 3, such traditional labour exchange exists in gauns based in the research area. One week after the aftershock, Community Forest Management Committees (CFMC) decided to open the forest for wood and timber in order to reconstruct temporary houses. In non-disaster periods, there is a system for paying the CFMC for timber and wood but CFMC supplied free of cost during emergency. International NGOs provided tin, toilet materials and repaired water tanks. Most of the people constructed their temporary shelter in ailani. They reconstructed the religious temples for festivals as religion base within gaun. Constructing temporary school buildings to continue classes for local children was done by all the neighbouring inhabitants. People engaged in harvesting crops individually or by perma as usual. Gauns gradually returned to their normal life despite the ongoing aftershocks which persisted.

\subsubsection{Reconstruction period}

When the government handed over subsidies as cash, gaun people started to reconstruct their own permanent residence by hiring labour. They also reconstructed the gaun community building economically supported by government and labour volunteered by themselves. Gradually, various coping programs such as awareness program, income generation training, safety training from earthquake, construction and plantation on slope land came to be provided at the ward level by through the collaboration of NGOs and VDC. The daily life of local people returned to normal situation when they got external aids by the government and NGOs. 
Despite the intense pressure caused by the earthquake and aftershock, in the research area, it was observed that communities maintained good social relations. This observation is based on the beliefs of the gaun people who expressed that social relations within their community had improved due to cooperation. This did not mean that there were no complaints about damage assessments or feelings of unfairness. There were many incidents such as losses, damages, casualties, injuries that led to increased tensions and the deterioration of social relations, nevertheless, gauns were able to maintain the mutual cooperation and social coherence regardless of ethnicity.

Table 4 Post-disaster activities done by local people

\begin{tabular}{|c|c|c|c|c|c|c|}
\hline \multicolumn{7}{|c|}{ Emergent Period } \\
\hline & \multicolumn{4}{|c|}{ Gaun Based } & Ward & VDC \\
\hline & Individual & Ethnic based & $\begin{array}{l}\text { Perma (hhs } \\
\text { based } \\
\text { labour } \\
\text { exchange } \\
\text { regardless } \\
\text { ethnicity }\end{array}$ & $\begin{array}{l}\text { Regardless } \\
\text { ethnicity }\end{array}$ & $\begin{array}{l}\text { Regardless } \\
\text { ethnicity }\end{array}$ & $\begin{array}{l}\text { Regardless } \\
\text { ethnicity }\end{array}$ \\
\hline $\begin{array}{l}\text { Normal } \\
\text { behaviour }\end{array}$ & & & & $\begin{array}{l}\text { used ailani (as } \\
\text { shelter) }\end{array}$ & & \\
\hline $\begin{array}{l}\text { Exceptional } \\
\text { behaviour }\end{array}$ & & $\begin{array}{l}\text { next day of } \\
\text { earthquake }> \\
\text { sharing } \\
\text { shelter, food, } \\
\text { clothes. }\end{array}$ & & $\begin{array}{l}\text { on the day of } \\
\text { earthquake }> \\
\text { helped injured } \\
\text { people, funeral } \\
\text { activity, } \\
\text { sharing food } \\
\text { stuff. }\end{array}$ & & \\
\hline \multicolumn{7}{|c|}{ Recovery Period } \\
\hline $\begin{array}{l}\text { Normal } \\
\text { behaviour }\end{array}$ & $\begin{array}{l}\text { harvesting } \\
\text { crops }\end{array}$ & $\begin{array}{l}\text { religiousand } \\
\text { ethnic events }\end{array}$ & $\begin{array}{l}\text { removed } \\
\text { house } \\
\text { wastes, } \\
\text { harvesting } \\
\text { crops, } \\
\text { constructed } \\
\text { temporary } \\
\text { shelter }\end{array}$ & & $\begin{array}{l}\text { income } \\
\text { generating } \\
\text { training, } \\
\text { awareness } \\
\text { programs }\end{array}$ & $\begin{array}{l}\text { income } \\
\text { generating } \\
\text { training, } \\
\text { awareness } \\
\text { programs }\end{array}$ \\
\hline $\begin{array}{l}\text { Exceptional } \\
\text { Behaviour }\end{array}$ & & & & \multicolumn{2}{|c|}{$\begin{array}{l}\text { Opening community free of } \\
\text { cost, construction of school } \\
\text { building voluntarily }\end{array}$} & $\begin{array}{l}\text { distribution of } \\
\text { construction } \\
\text { materials to } \\
\text { the hhs. }\end{array}$ \\
\hline \multicolumn{7}{|c|}{ Reconstruction Period } \\
\hline $\begin{array}{l}\text { Normal } \\
\text { behaviour }\end{array}$ & $\begin{array}{l}\text { Construction } \\
\text { of private } \\
\text { building by } \\
\text { hiring labour }\end{array}$ & & & $\begin{array}{l}\text { community } \\
\text { building } \\
\text { reconstruction. }\end{array}$ & & \\
\hline $\begin{array}{l}\text { Exceptional } \\
\text { behaviour }\end{array}$ & & & & & & \\
\hline
\end{tabular}

Source: Field study, 2018

Table 4 is the summary of local people's activities on three periods focusing on 1) normal behaviour and exceptional behaviour, 2) informal and formal local unit 3) the ethnicity.

In this case study, we compared the resources between informal and formal local unit in the research area. Ward and VDC based resources are newly formed and cooperated regardless of ethnicity. Various cooperation was observed regardless of ethnicity in gaun level. 
Observing above mentioned local people's actions in three periods, they were found in normal and exceptional mode at different local levels. Most of the activities were exceptional regardless of ethnicity. Most exceptional activities were observed in emergent period specially the day of the disaster. Various cooperation was observed which is normally conducted within ethnicity. The reason why such cooperation beyond the ethnicity was realized that resources which are indispensable for maintaining everyday life are managed by gaun regardless of ethnicity in normal period. As Wang et al. (2017) pointed out, the villagers shared same natural environment.

As shown in Table 3, a gaun is the basic minimal informal social unit closely connected to local inhabitants, while ward and VDC are formal administrative units in the local level. Gaun based local resources are typically traditional and primary that sustain people in their daily life. Thus local people could change their behaviour so quickly at the danger of their lives. It was noticeable that food and clothes were shared irrespective of ethnic groups at the day of the earthquake, but on the next day, it returned to within ethnicity as normal mode. It may be because they thought they could withstand their critical period. This kind of flexibility shown by local autonomous communities was reported by Yoshino (2017) in Sanriku area at the time of East Japan Great Earthquake in 2011. After the recovery period, most activities were done in normal mode in gauns except for community forest management. The free use of timber for the construction of individual shelter was exceptionally allowed because of the damage to homes inflicted by the earthquake.

VDCs also relied on gauns for the distribution of aid materials. As mentioned above local government acknowledges gauns as the functioning minimum local unit although they are informal.

\section{Conclusions}

The earthquake that hit Nepal in 2015 devastated country. Disaster risks are often approached in technical and physical manner. However, socio-cultural factors are also important for disaster management focusing on mutual support, community institutions, allocation and use of resources and recovery measures. This paper analysed local people's behaviour and its basic logic during post-earthquake recovery from a sociocultural aspect focusing on gauns, the basic minimal informal social unit paying attention to ethnically heterogeneity of community. This study revealed that gaun based local resources are traditional and primary resources for the people's daily life whereas ward based and VDC based organizations are newly formed. Among the 14 gauns, three gauns were composed of multiple ethnic groups with a majority of tamang and minority of dalit where various forms of cooperation was observed regardless of ethnicity.

Local people's activities towards disaster recovery was categorized into three periods: emergent, recovery and reconstruction. Local people's actions during these three post-disaster recovery periods were observed as either normal or exceptional. It was found that during the emergent period, there were more exceptional actions taken by local people, specifically with regards to inter-ethnic group cooperation. Primary resources are essential to the survival such as food and clothing were shared among ethnic groups in the immediate aftermath of the disaster. However, in recovery and reconstruction periods, local people's behaviour returned to normal with the exception of community forest and timber management where the extraction of timber was 
permitted for free due to the need for reconstructing shelter destroyed by the earthquake.

The basic unit for local people's livelihood was gaun. When there are plural ethnic groups in one gaun, the basic primary resources are used collectively regardless of ethnicity. The principle of gaun management for every household in gaun is to be able to meet daily life basic needs. This principle functioned at the critical period after the disaster, accompanying exceptional behaviours beyond ethnicities by local people because of the seriousness of the damage which could not be solved within ethnicity.

\section{Acknowledgement}

The authors acknowledge the Hasegawa International Student Scholarship Foundation for funding this research and would also like to express our gratitude to all local inhabitants of Betini, Nuwakot, Nepal.

\section{References}

Bolin, R., 1976. Family recovery from natural disaster: A preliminary model. Mass Emergencies, 1: 267-277.

Central Bureau of statistics, 2006. Headcount poverty rate in Nepal. Government of Nepal: National Planning Commission.

Central Bureau of statistics, 2011. Population Census 2011. Government of Nepal: National Planning Commission.

District Disaster Relief Committee, 2015. Nepal Earthquake Disaster Profile, Nuwakot. May 15, 2015. District Administrative Office, Nuwakot, Nepal.

Hewitt, k., 2008. Culture and Risk: Understanding the socio-cultural settings that influence risk from natural hazards. Synthesis Report from a Global EConference. 2008, $22^{\text {nd }}$ September- $3^{\text {rd }}$ October. ICIMOD, Kathmandu, Nepal.

Kapucu, N., 2008. Culture of preparedness: Household disaster preparedness. Disaster Preventive and Management, 17 (4), pp: 526-535.

Mercy Corps, 2016. Nepal earthquake Report 2015. Retrieved from https://www.mercycorps.org/

Mishra, A., Ghate, R., Maharjan, A., Gurung, J., Pathak, G., \& Upraity, A. N., 2017. Building ex ante resilience of disaster-exposed mountain communities:

Drawing insight from the Nepal earthquake recovery. International Journal of Disaster Risk Reduction, 22, pp: 167-178.

Ministry of Home Affairs \& Disaster Preparedness Network, 2009. National Disaster Report 2009. Government of Nepal.

Post Disaster Need Assessment, Vol. A. 2015. Nepal Earthquake 2015. Government of Nepal: National Planning Commission.

Wang, Y., Zhu, Y., \& Sui, Q., 2017. Ethnic Group Differences in Domestic Recovery after the Catastrophe: A Case Study of the 2008 Magnitude 7.9 Earthquake in China. International Journal of Environmental Research and Public Health, 14, pp: 1-13.

World Bank, 2016. National Human Development report. Kathmandu, Nepal.

Yoshino, K., 2017. TURFs in the post-quake recovery: Case studies in Sanriku fishing communities. Marine Policy (Elsevier), 86, pp: 47-55 